BULLETIN Bulletin hispanique

HISPANIQUE Université Michel de Montaigne Bordeaux

$119-2 \mid 2017$

La Égloga renacentista en el Reino de Nápoles

\title{
Las anotaciones de Gregorio Mayans a República
} literaria

Sònia Boadas

\section{(2) OpenEdition}

1 Journals

\section{Edición electrónica}

URL: http://journals.openedition.org/bulletinhispanique/5225

DOI: 10.4000/bulletinhispanique.5225

ISSN: 1775-3821

\section{Editor}

Presses universitaires de Bordeaux

\section{Edición impresa}

Fecha de publicación: 1 diciembre 2017

Paginación: 757-772

ISBN: 979-10-300-0218-8

ISSN: 0007-4640

\section{Referencia electrónica}

Sònia Boadas, «Las anotaciones de Gregorio Mayans a República literaria», Bulletin hispanique [En línea], 119-2 | 2017, Publicado el 28 diciembre 2020, consultado el 15 enero 2021. URL: http:// journals.openedition.org/bulletinhispanique/5225; DOI: https://doi.org/10.4000/bulletinhispanique. 5225 


\title{
Las anotaciones de Gregorio Mayans a República literaria ${ }^{1}$
}

\author{
SÒNIA BOADAS \\ Universitat Autònoma de Barcelona
}

Cet article a pour objectif d'analyser l'intérêt que l'érudit valencien Gregorio Mayans a porté à Diego de Saavedra à travers la découverte d'un codex inédit de plus de cinq cents pages avec des notes autographes de Mayans à la República literaria.

Mots-clés: Gregorio Mayans, República literaria, Diego de Saavedra.

Este artículo pretende ahondar en el interés que el erudito valenciano Gregorio Mayans tuvo por Diego de Saavedra a través del descubrimiento de un códice inédito de más de quinientos folios con notas autógrafas de Mayans sobre la República literaria.

Palabras clave: Gregorio Mayans, República literaria, Diego de Saavedra.

This article aims to go deeper into the interest that the Valencian scholar Gregorio Mayans had in Diego de Saavedra, through the discovery of an unpublished manuscript of over five hundred pages, with Mayans' autograph notes on the 'República Literaria'.

Keywords: Gregorio Mayans, República literaria, Diego de Saavedra.

1. Este trabajo se enmarca dentro del Proyecto FFI2011-22929 «Diego de Saavedra Fajardo y las corrientes intelectuales y literarias del Humanismo", financiado por el Ministerio de Economía y Competitividad. 
«Digo pues, que no ha logrado España un varón tan elocuente como don Diego Saavedra». Así es como a mediados de la década de los veinte del siglo XVIII el erudito valenciano Gregorio Mayans ensalzaba a uno de los principales prosistas españoles en su Oración en alabanza a las obras de don Diego de Saavedra. De hecho, no fue el único que elogió la obra del literato y diplomático murciano, ya que a lo largo del siglo XVIII la obra de Saavedra suscitó notable interés entre los escritores ilustrados, como Benito Jerónimo Feijoo o Antonio de Capmany y de Montpalau².

Entre ellos cabe destacar también a Tomás de Iriarte (1750-1791), quien leyó con atención las obras del murciano y tuvo especial interés en el texto de República literaria. De hecho, llegó a corregir diligentemente un ejemplar de la edición de Porres (Madrid, 1670), que en la actualidad se conserva en la Boston Public Library (signatura RARE BKS D.167.26), donde se pueden apreciar varias anotaciones, al parecer autógrafas, de Iriarte $^{3}$. Estas notas tienden a corregir errores de lengua y gramática, así como introducen ciertas aclaraciones, palabras y frases cortas que ayudarían al buen entendimiento del texto ${ }^{4}$.

Por otra parte, y como hemos empezado mencionando, es bien conocido el juicio crítico que Gregorio Mayans (1699-1781) hizo de la obra y del estilo literario del murciano en su Oración en alabanza a las obras de Diego de Saavedra Fajardo, publicada por primera vez en 1725 . A pesar de las críticas que le valió este tratado, Mayans no cesó en el estudio de la obra de Saavedra y, al igual que a Iriarte, le llamó especialmente la atención el texto de República literaria, de la

2. Véase el artículo de Belén Rosa de Gea, «Estelas de Saavedra Fajardo: sus obras, sus lectores", Res publica, no 19, 2008, p. 449-472.

3. En uno de los primeros folios del impreso aparece una anotación manuscrita de George Ticknor donde se afirma que «This copy of the República literaria was obtained by O. Rich from the Library of Thomas de Yriarte and contains the emendations in his autograph, that he made to prepare it for the press». En el folio siguiente encontramos otra anotación manuscrita de alguien que firma con las iniciales «M.R.» que asevera: «En esta edición original, donde hay muchas notas o correcciones hechas por uno de los Iriartes (según atestigua el Sr. don Guillermo O. Rich, que compró la librería de don Tomás y la trajo aquí a vender últimamente). Solo se nota que se ha tratado de corregir los defectos de lenguaje y gramática, y añadido solo una que otra palabra o corta frase para hacerlo más liso, grato, armonioso y más inteligible.» Sin embargo, Leighton, después de cotejar las enmiendas manuscritas con los autografos de Iriarte, considera que podrían no ser de la misma mano. Véase Charles H. Leighton, «Sobre el texto del Diálogo entre el amor y un viejo, Nueva Revista de Filología Hispánica, XII, no 3/4, 1958, p. 385-389.

4. Francisco Javier Díez de Revenga, "Juicios dieciochescos sobre Saavedra Fajardo», Monteagudo, no 56, 1976, p. 5-10, John Dowling, «Saavedra Fajardo’s República Literaria: The bibliographical history of a little masterpiece», Hispanófila, no 67, 1979, p. 7-38; no 68, 1980, p. 11-27; no 69, 1980, p. 27-44 y Joaquín Álvarez Barrientos, «Sobre la edición de 1788 de la República Literaria de Diego de Saavedra Fajardo», en José Checa Beltrán (coord.), El siglo que llaman ilustrado. Homenaje a Francisco Aguilar Piñal, Madrid, CSIC, 1996, p. 55-62. 
cual publicó una primera edición en 1730 (Valencia, Antonio Balle). Es muy probable que el interés que estos eruditos españoles mostraron por Saavedra, y especialmente la labor editorial y filológica que impulsó Gregorio Mayans, provocara una revalorización notable de las obras saavedrianas en la Europa del siglo XVIII.

\section{MaYANS y LA DIFUSIÓN De REPÚBLICA LITERARIA}

Los elogios que un joven Gregorio Mayans dedicó al estilo literario de Diego de Saavedra en Oración en alabanza son harto conocidos. Esta inclinación hacia la obra de Saavedra no se cińe estrictamente a esta obra panegírica sino que de una manera u otra se dilatará a lo largo de prácticamente toda su vida. Recordemos las diferentes ediciones de República literaria, así como las citas constantes de Saavedra en la Retórica mayansiana, donde el autor de Empresas politicas se convierte en uno de los escritores más citados 5 . De esta manera, las relaciones que don Gregorio estableció con numerosos impresores y mecenas europeos catapultaron la obra de Saavedra, y más especialmente República literaria, a la esfera internacional.

Los primeros contactos con Francia se establecieron a principios de la década de los treinta a través del impresor lionés Roque Deville, a quien Mayans envió, entre otros libros, su Oración en alabanza a las obras de Diego de Saavedra (1725) y una edición de República literaria (1730) ${ }^{6}$. Ya en las primeras cartas que se intercambió con Deville, el valenciano destacaba la necesidad de publicar un volumen de correspondencia en el que aparecieran epístolas de Saavedra Fajardo: «En España hay falta de un buen libro de cartas. Yo tengo 25 inéditas de $\mathrm{D}$. Antonio de Solís y sería fácil recoger algunas más de Quevedo, Saavedra y otros y se podría formar un tomo muy acepto a la nación» ${ }^{7}$. Pocos años después, el impresor lionés insistía en querer publicar las obras de los principales escritores españoles: «Como deseamos imprimir las obras de Quevedo y desearíamos tener un juego muy correcto si fuese posible y no tardaríamos en imprimirlo así como otros muchos como Dávila, Solís, Saavedra, y empezaríamos por los que $\mathrm{Vm}$. nos aconsejase» ${ }^{8}$. Sin embargo, las

5. Gaspar Garrote Bernal, «El canon de prosistas áureos en la Retórica de Mayans», en José Lara Garrido y Belén Molina Huete (eds.), La literatura del Siglo de Oro en el Siglo de la Ilustración. Estudios sobre la Recepción y el Canon de la Literatura Española, Madrid, Visor Libros, 2013, p. 41-58.

6. Antonio Mestre, «Relación epistolar-cultural entre el editor lionés Roque Deville y Mayans", Revista de historia moderna, no 5, 1985, p. 141-155.

7. Mayans a Deville, sin fecha, 1731. Biblioteca Archivo Hispano Mayansiano del Colegio de Corpus Christi de Valencia (= BAHM), 149. Véase Gregorio Mayans, Epistolario XII. Mayans y los libreros, Antonio Mestre (ed.), Valencia, Publicaciones Ayuntamiento de Oliva, 1993, p. 289.

8. Deville a Mayans, 6 de diciembre de 1732, BAHM, 54. Ibid., p. 329. En este mismo sentido volvió a escribir Deville pocas semanas después: «En cuanto a las impresiones de Quevedo, Gracián, Solís y Saavedra, si Vm. nos pudiera procurar las ediciones que convienen en adelante los haremos imprimir.» Deville a Mayans, 28 de febrero 1733, BAHM, 54. Ibid., p. 333. 
relaciones con este impresor acabaron siendo infructuosas y la mayoría de estos libros no llegaron a publicarse.

Más éxito tuvo la relación de Mayans con el impresor François Grasset, con quien negoció la publicación de la traducción francesa de República literaria. En una carta de 11 de febrero de 1765 Mayans le comunicaba: «Me alegro de que Vm. haya ofrecido publicar una traducción francesa de República literaria de don Diego de Saavedra, que confío será bien recibida» ${ }^{9}$. Grasset no tardó en responder, dando cuenta de los ejemplares que enviaría al valenciano: "Je vous addresserai dans quelques expéditions à Valence ou à Alicante l'original de la République Littéraire de Saavedra et quelques exemplaires de la traduction Françoise tant pour vous que pour vos amis ${ }^{10}$ ». Efectivamente, tal y como le había prometido Grasset, en 1770 la traducción francesa apareció en letras de molde, impresa en un taller de la localidad suiza de Lausanna ${ }^{11}$.

Algunos años antes, Mayans también había establecido contactos con Gabriel Cramer. Las conversaciones con este impresor suizo versaron de nuevo sobre la necesidad de traducir e imprimir el texto de República literaria, precisándole cuál debía ser la edición de referencia para la traducción. En los siguientes términos se expresaba Mayans en una carta de 6 de marzo de 1751:

En caso de querer $V m$. ejercitarse en traducir algún librito de la lengua española en la francesa, ninguna mejor que la República literaria de don Diego de Saavedra Fajardo de la impresión que yo hice en Madrid, que es la más correcta, y es necesaria esta advertencia porque la que $\mathrm{Vm}$. tiene de Alcalá, en la p. 8 del catálogo de los libros españoles, está llena de errores muy enormes. El lenguaje deste librito de Saavedra es castísimo y enmendado, y la obra es de ingeniosa y agradable invención, digno de estar en una y otra lengua ${ }^{12}$.

Nada más sabemos acerca de esta posible traducción, que seguramente no llegó a aparecer en letras de molde. Por otra parte, las relaciones que estableció Mayans con el barón Schönberg fueron primordiales para la difusión de la obra de Saavedra en Alemania ${ }^{13}$. Mayans y el Barón se habían conocido en 1730, cuando el de Schönberg se encontraba de visita en España. A partir de ese momento, empezaron unos intensos y fructíferos intercambios epistolares. A finales de la década de los treinta, Mayans envió a Schönberg un ejemplar de República literaria ${ }^{14}$, edición sobre la que probablemente se basaría la

9. Ibid., p. 424.

10. François Grasset a Gregorio Mayans, 9 de mayo de 1765. Íbid., 425.

11. La obra rezaba La République Littéraire, ou Description allégorique et critique des sciences et des Arts [...]. Traduit de l'Espagnol, sur l'édition la plus correcte, publié à Madrid en 1735. Lausanne, François Grasset, 1770.

12. Gregorio Mayans, Epistolario. Mayans y los libreros, Antonio Mestre (ed.), Valencia, Publicaciones Ayuntamiento de Oliva, 1993, p. 274.

13. Antonio Mestre, «Mayans, die spanische Kultur und Deutschaldn im 18 Jahrhundert», dans Elmar Mittler y Ulrich Mücke (eds.), Eine Ausstellung aus den Beständen der Niedersächsischen Staatsund Universitätsbibliotek Göttingen, Gotinga, s.i., 2005, p. 55-66.

14. Mayans a Schönberg, 2 de junio de 1738. Gregorio Mayans, Epistolario. Mayans y el Barón de Schönberg, Antonio Mestre (ed.), Valencia, Publicaciones Ayuntamiento de Oliva, 2002, p. 103. 
traducción alemana Die Gelehrte Republic, que además apareció acompañada de la traducción de Oración en alabanza a las obras de Diego de Saavedra ${ }^{15}$. Se desconoce quién fue el impulsor de la traducción alemana de estos textos, aunque muy probablemente fuese Schönberg o alguien cercano a él. El encargado de traducir el texto al alemán fue Johann Erhard Kapp ${ }^{16}$, catedrático de la universidad de Leipzig, y la obra se publicó en 1748 en el taller de los Gleditsch en Leipzig ${ }^{17}$. A pesar de todo, es posible que Mayans no tuviera noticia de esta edición alemana, ya que no se encuentra mención alguna en sus textos o cartas $^{18}$.

Algunos años después, en 1771, se publicó una segunda traducción alemana del texto en Praga, en el taller de Felician Mangold, con un título ligeramente diferente: Die Republik der Gelehrten ${ }^{19}$. En esta ocasión, el texto base para la traducción no habría sido la edición en castellano de Mayans, sino la traducción francesa publicada por Grasset (Lausana, 1770).

Por otra parte, es también conocida la amistad que Mayans trabó con el embajador inglés en España, Benjamin Keene (1697-1757). Si bien no se puede establecer una relación directa entre Mayans-Keene y la segunda traducción inglesa de República literaria, publicada en $1728^{20}$, entre otros motivos porque

15. El título completo rezaba: Die gelehrte Republic durch Don Diego Saavedra, Ritter des St. Jacobs- Orden, Beysitzer des obersten Raths von Indien und Philipp des Vierten, Königs in Spanien, gevollmächtigten Gesandten, auf der Friedensversammlung zu Münster. Nebst Gregorii Mayans Lobrede auf die wohlgeschriebenen Werke des Saavedra, und des Herrn le $C^{* * *}$ gelehrten Republic davon die beyden ersten Schriften aus dem Spanischen, die letzte aber aus dem Französischen übersetzet worden. Mit einer Vorrede und einigen Anmerkungen Herrn Joh. Erhard Kappens, Professoris zu Leipzig.

16. Johann Ehrhard Kapp fue catedrático de retórica en la Universidad de Leipzig y alumno, a su vez, del bibliófilo Johann Burckhardt Mencke, uno de los lectores alemanes de Saavedra Fajardo. En la biblioteca de Mencke se conservaban ejemplares de Corona Gótica (Amberes, 1659), de Idea de un principe político-cristiano (Ámsterdam, 1659) y de República literaria (Alcalá de Henares, 1670). Véase Friedrich Otto Mencke y Johann Burckhardt Mencke, Bibliotheca Menckeniana, quae autores praecipue veteres graecos et lat. historiae item literarie, Leipzig, Gleditsch, 1727, vol. 2, p. 389, 523.

17. También es muy probable que surgiera de este taller de Leipzig la traducción alemana del diálogo saavedriano Locuras de Europa, que apareció el mismo año de 1748 bajo el título Die Thorheiten von Europa. Véase Sònia Boadas y Folke Gernert, «Lectores de Saavedra en la Alemania Ilustrada: Leipzig y la traducción alemana de Locuras de Europa», Studia Aurea, no 4, 2010, p. 81-103.

18. De hecho, la relación epistolar entre Mayans y el barón de Shönberg terminó en 1740, lo que podría explicar que el valenciano desconociera la existencia de la traducción alemana de República literaria.

19. El título completo rezaba: Die Republik der Gelehrten oder allegorische und kritische Beschreibung der Künste und Wissenschaften; welche von Dom Diego Saavedra Fajardo, Ritter des Ordens von St. Jago u.s.w. hinterlassen worden, und nach dessen Tode in Spanischer Sprache ans Licht getreten. Nach der Französischen Ausgaben. Esta traducción alemana fue reimpresa en JenaLeipzig por Gabler en 1807.

20. La primera traducción de la obra se publicó en 1705 bajo el título The commonwealth of learning. La segunda versión inglesa reza: Respublica Literaria: or the Republick of Letters; being a vision. Wrote in Spanish by Don Diego de Saavedra, Knight of the Order of St. James. Dedicated 
esta versión fue anterior a la edición mayansiana de 1730, sí podemos afirmar que la amistad entre estos dos personajes fue tal que el español decidió dedicar la segunda edición de República literaria (Madrid, Juan de Zúñiga, 1735) al embajador inglés ${ }^{21}$.

\section{Un CÓdicE MANUSCRITO INÉDito DE MaYANS}

Como se deduce del texto de Oración en alabanza que transcribo a continuación, la voluntad de Gregorio Mayans en 1725 se centraba en dar a conocer una versión enmendada de República literaria, acompañada de unas breves notas que permitiesen la correcta comprensión de determinados fragmentos:

Por fin don Diego Saavedra, en lo que toca a inventar ingeniosamente, ha llegado a tanto, que ha vencido a todos. Él fue el que con maravilloso artificio levantó sobre profundos cimientos de solidísima erudición la República literaria, cuyos beneméritos ciudadanos vivían antes esparcidos por tantos siglos. Es pues ocultísima su erudición, conocida sólo de los que con muy copiosa lección han fatigado su vista. Su agudeza, discreción y gracia son incomparables; el estilo, inimitable, y por último todo el libro tal que sólo él debe bastar, en mi juicio, para que don Diego se tenga por un varón sumamente juicioso, sabio y elocuente.

Mi sentimiento es que desfigurase tanto la malicia este libro, publicándole primero mutilado, y con el mentido nombre de falso autor, don Claudio Antonio de Cabrera. Desconoció al impostor y libro don Nicolás Antonio, sagacísimo juez de supositicios libros, de donde infiero yo que no debió leerle. Después le vindicó a su legítimo dueño, don Josef de Salinas, pero sin hacer mención de la impresión primera y afeando la segunda miserablemente con notabilísimos descuidos y muy enormes yerros. Quiera dios que algún día le publique yo restituido a su primitivo ser, y añadiendo para su declaración unas breves notas, dé a conocer al Mundo esta admirable obra. Procuraré entonces desahogar mi pecho, y con el testimonio que daré de su profunda erudición, podré hablar con libertad mayor. Ahora me contento con una breve y escasa apuntación de sus inmortales prendas, y me dedicaré de nuevo a estudiarle mejor para repetir sus alabanzas más dignamente ${ }^{22}$.

to his Excellency John Lord Carteret. London, Samuel Fuller, 1728. Strodtmann estableció esta relación -sin aportar más datos al respecto- en su libro sobre la vida de Mayans. Véase Iohannes Christophorus Strodtmann, Gregorii Maiansii, Generosi Valentini, Vita, Valencia, Ayuntamiento de Oliva, 1974, p. 292-293.

21. La dedicatoria reza: «Al excelentísimo señor don Bejamin Keene, ministro plenipotenciario del Rey de la Gran Bretaña, Jorge Augusto II, cerca del Rey de las Españas, Nuestro Señor, don Felipe V». Véase Antoni Pesset Llorca, Antoni Mayans i la cultura de la Ilustració, Barcelona, Curial, 1975 y Antonio Mestre, Apología y crítica de España en el siglo XVIII, Madrid, Marcial Pons, 2003, p. 132-135. Para la relación entre Keene y Mayans véase Strodtmann, op. cit., p. $92-97$.

22. La cursiva es mía. Véase Gregorio Mayans, Oración en alabanza de las elocuentísimas obras de Don Diego Saavedra Fajardo, Valencia, Antonio Bordazar, 1725, p. 22 y también en Gregorio Mayans, Obras completas, Antonio Mestre (ed.). Oliva, Ayuntamiento de Oliva, 1983. 
Siguiendo el objetivo de publicar una versión corregida del texto, pocos años después, en 1730, aparecía en Valencia su ya citada edición de República literaria $^{23}$. Sin embargo, los comentarios al estilo de Saavedra que publicó en su Oración no tardaron en despertar opiniones adversas. Así lo resumía el mismo Mayans en sus Pensamientos Literarios de 1734:

Por el mismo deseo de introducir en España la historia literaria, años ha que hice (en el mayor hervor de mi adolescencia) unos apuntamientos para formar unos comentarios sobre la República literaria de don Diego Saavedra Fajardo, y queriendo explorar cómo se recibirían anticipé una oración, al parecer en alabanza de aquel mismo autor, pero verdaderamente crítica, y se recibió de manera que escandalizándose muchos de la libertad del decir (aunque, cierto, muy moderada) me retraje del intento ${ }^{24}$.

A pesar de las críticas, que en un primer momento parecen frenar las expectativas del erudito valenciano, en la última reedición de su Oración, que se imprimió en 1739, encontramos unos leves cambios en el discurso de Mayans que denotan la voluntad de continuar con la correcta anotación de República literaria. A propósito de los errores de la obra anotó: «Destos ya le libré pocos años ha, preocupé y satisfice a la censura en que pudo don Diego haber incurrido. Quiera Dios que algún día añada yo algunas notas para su mayor inteligencia» ${ }^{25}$.

Estas notas a las que hace referencia Mayans, los supuestos apuntamientos a República literaria, no se incorporaron en ninguna de sus posteriores ediciones de la obra y han permanecido desconocidas hasta la actualidad. Algunos años después, en una carta que Mayans envió a Fernando Velasco el 3 de enero de 1763, don Gregorio daba de nuevo noticia de sus apuntes ${ }^{26}$ : «En cuanto a mis manuscritos, a nadie he querido dar puntual noticia de ellos, porque no parezca increíble. A V.S. diré generalmente que la mayor parte de ellos son apuntamientos, unos sueltos por orden del abecé o cronológicamente, variamente amontonados, ya en libros misceláneos y reducidos a las artes y ciencias», entre los cuales se encontraba «un tomo de apuntamientos de más de quinientas hojas en cuarto sobre la República literaria de Saavedra ${ }^{27}$ ».

Así pues, todos los datos hasta aquí aducidos indican que Mayans había elaborado un tomo de anotaciones inéditas al somnium saavedriano que hasta

23. La obra rezaba República Literaria. Obra póstuma. Sale a luz corregida diligentemente según una copia manuscrita de don Gregorio Mayans, Valencia, por Antonio Balle, 1730.

24. En Gregorio Mayans, Obras completas, I. Historia, Antonio Mestre (ed.), Oliva, Ayuntamiento de Oliva, 1983, p. 256.

25. Véase Gregorio Mayans, Obras Completas, II, Antonio Mestre (ed.), Oliva, Ayuntamiento de Oliva, 1984, p. 539-564.

26. Ya en 1745, en su correspondencia con Burriel, Mayans afirmaba tener un tomo en cuarto con más de 400 hojas sobre República Literaria. Véase Sònia Boadas, «Un artífice español que debe su ser a las riberas del río Segura: Mayans y un pasaje incomprendido de República literaria", Rassegna Iberistica, vol. 38, no 104, 2015, p. 229.

27. Gregorio Mayans, Epistolario, XVI: Mayans y los altos cuadros de la Magistratura y Administración borbónica, Antonio Mestre y Pablo Pérez García (ed.), Valencia, Ayuntamiento de Oliva, 1998, p. 234. 
ahora han pasado inadvertidas a los estudiosos de ambos autores. Gracias al rastreo documental de los fondos conservados en la Biblioteca del Real Colegio Seminario del Corpus Christi (Real Colegio del Patriarca) de Valencia, estos apuntamientos han salido a la luz, ya que, en efecto, esta biblioteca custodia un volumen de anotaciones manuscritas inéditas de Gregorio Mayans a República literaria. Se trata del volumen Ms. 229 de la Biblioteca Archivo Hispano Mayansiano $(\mathrm{BAHM})^{28}$, un códice en cuarto de más de quinientos folios con centenares de anotaciones autógrafas del erudito valenciano a la obra de Saavedra.

En general, las notas que añadió Mayans son de diversa índole, desde apreciaciones sobre las fuentes que utilizó don Diego, hasta aclaraciones sobre el significado de varios pasajes, o incluso ampliaciones de determinada información a través de varias citas de los clásicos. Estamos ante unas anotaciones de carácter crítico que permiten descubrir qué visión tenía Mayans de la obra y de su autor.

Por lo que se refiere a la foliación, el códice de anotaciones presenta una numeración particular. Los números aparecen en la parte superior derecha de las páginas pero no siguen un orden consecutivo, sino que hacen referencia a la localización de las palabras anotadas en la edición de República literaria que utilizaba Mayans. Es decir, que cuando aparece el número «12» en el códice de anotaciones manuscritas significa que las palabras que están copiadas en esa página aparecen en la página 12 de la edición de República literaria (Valencia, Antonio Balle, 1730), que era la que utilizaba Mayans como base para sus apuntamientos. De la misma manera, los números «6-7» en la parte superior indican que las expresiones que se comentan en ese folio se encuentran en las páginas 6 y 7 de la edición impresa de 1730 .

Como vemos, su metodología de trabajo era particular. Suponemos que en primer lugar copiaba las páginas en el margen superior derecho, junto a la palabra o el breve texto de República literaria objeto de comentario. A continuación, el valenciano exponía su aclaración, ampliaba la información o añadía los comentarios que consideraba oportunos. Estas glosas se fueron revisando y ampliando en fases posteriores. Así se explican, por ejemplo, las hojas que se añadieron al volumen, la existencia de varios folios en blanco a lo largo del códice, la diferente tinta de algunas notas, la aparición de varias entradas sin la correspondiente anotación, como si estuvieran pendientes de redacción, o incluso la repetición de entradas, en las que se complementa o amplía la información dada.

Vale la pena señalar que estos apuntamientos son fruto de una labor que se extendió a lo largo de varios años, y que por lo tanto, la reelaboración y constante inclusión de fragmentos ponen también de manifiesto la evolución

28. «República literaria de Saavedra, ilustrada con notas propias y de su letra, en cuarto». Véase Ma J. Martínez Alcalde, Las ideas lingüisticas de Gregorio Mayans: tesis doctoral. Valencia, Universitat de València, Servicio de Publicaciones, 1991. 
del pensamiento de Mayans ${ }^{29}$. Este proyecto precisaba de una reescritura y de una revisión permanente, que muestra hasta qué punto era ambicioso el deseo de Mayans y al mismo tiempo cómo nunca llegó a culminarse. Estamos, pues, ante un proceso de ampliación y de relectura que no cesó a lo largo de varios años, en el cual siempre era posible añadir una nota más. Así lo confesaba el mismo Mayans en una carta a Fernando Velasco del 10 de enero de 1763:

Ya obedecí a V.S. el correo pasado enviando una noticia, aunque diminuta, de los principales asuntos que tengo trabajados, de los cuales quisiera yo perfeccionar una media docena, y con eso estaría satisfecho de mi aplicación, como son: la Edad de Jesucristo, la Gramática Latina, que enseñará toda la lengua y su uso. [...] La Retórica Latina, en que recogeré todo lo que se ha dicho sobre la perfección de pensar y hablar, un doctrinal De las obligaciones humanas, fundado solamente en la razón natural y divinas letras. Un comentario sobre la República literaria de Saavedra y la Filosofía Moral en castellano ${ }^{30}$.

\section{Algunas anotaciones de Mayans a República literaria}

No hay duda que un códice de tales características precisa de un estudio detallado para dilucidar la opinión que le merecía al erudito valenciano tanto Diego de Saavedra como su República literaria. Por el momento, me dispongo a ofrecer una pequeña muestra de lo harto variadas que pueden llegar a ser las explicaciones que añadió Mayans, una sucinta selección de algunas anotaciones que me han parecido particularmente interesantes.

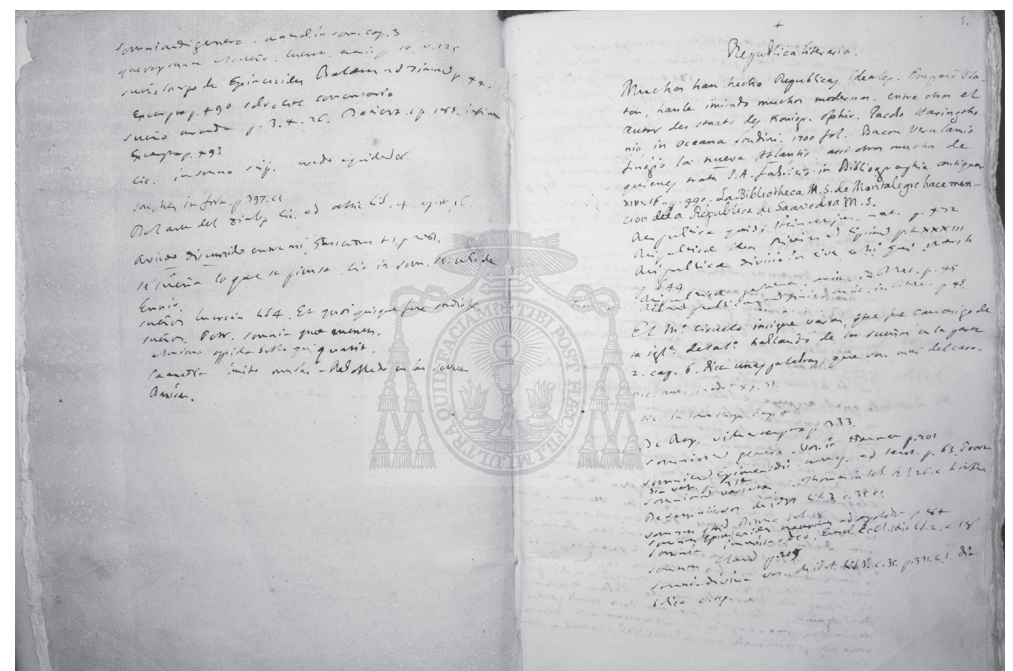

Imagen del manuscrito de anotaciones de Mayans, Ms. 229 (BAHM)

29. En otras ocasiones, son las mismas notas autógrafas las que reflejan la rapidez con que a veces debía reseñar. Dice Mayans: «Sino escribiera yo tan de prisa estas notas, copiaría aquí unos versos de D. Francisco de Quevedo en ocasión de recordar al papel su humilde origen.» Anotaciones de Mayans a la República literaria, BHAM, 229.

30. Véase Gregorio Mayans, Epistolario. Volumen XVI: Mayans y los altos cuadros de la Magistratura y Administración borbónica, Antonio Mestre y Pablo Pérez García (ed.), Valencia, Ayuntamiento de Oliva, 1998, p. 235-236. 
Nada más empezar, en la primera página, aparece una nota muy curiosa a propósito de un manuscrito supuestamente perdido de República literaria. Dice Mayans: «La biblioteca M.S. de Montalegre hace mención de la República Literaria de Saavedra M.S.» Se trata de una nota que no nos deja indiferentes, por lo que hemos recurrido al catálogo de La colección de manuscritos del Marqués de Montealegre (1677), para verificar dicha información. Efectivamente, en este catálogo aparece una entrada que refiere un códice de República literaria de Saavedra Fajardo ${ }^{31}$. Según indica Rodríguez Moñino, gran parte de los fondos de la biblioteca del Marqués de Montealegre fueron a parar a la biblioteca y archivo del cronista don Luis de Salazar, y por lo tanto, algunos años después entraron a formar parte de la Real Academia de la Historia. Sin embargo, en ninguno de los catálogos de esta institución aparece dicho manuscrito, por lo que probablemente o desapareció o anda perdido en alguna biblioteca extranjera ${ }^{32}$.

Otra de las anotaciones del valenciano guarda relación con el género de la obra, el somnium humanista. El erudito hace una apreciación a las primeras frases de Saavedra, cuando se produce la ensońación del narrador. Así lo expresó el murciano:

Habiendo discurrido entre mí del número grande de los libros, y de lo que va creciendo cada día, así por el atrevimiento de los que escriben, como por la facilidad de la Imprenta, con que se han hecho ya trato y mercancía las letras, y escribiendo para granjear, me venció el sueño y luego el sentido interior corrió el velo a las imágenes de aquellas cosas, en que despierto discurría ${ }^{33}$.

A lo que don Gregorio añadió:

Como ordinariamente los sueños suelen representar las especies en que más se piensa de día, para hacer D. Diego Saavedra más verosímil su sueño finge que despierto discurría del número grande de los libros y de lo que va creciendo. Imitó en esto a su contemporáneo D. Francisco de Quevedo en el Sueño de las Calaveras, o a D. Lorenzo de Van der Hammen, verdadero autor de la Casa de los locos de Amor, falsamente atribuida a su amigo íntimo D. Francisco de Quevedo. Imita también a Justo Lipsio en su insigne sátira menipea y a Lluís Vives, a Cicerón según Macrobio, y a otros muchísimos.

31. «164. República Literaria, por don Diego de Saavedra Faxardo, y aunque anda impresa, es la que volvió a reformar el año de 1612 en fol. M.S». Véase Antonio Rodríguez Moñino, La colección de manuscritos del Marqués de Montealegre (1677), s.l., 1951, p. 54.

32. Otro testimonio manuscrito de República literaria se conservaba en 1868 en la Biblioteca de la Universidad de Ońate, según consta en el catálogo que mandó realizar el rector de esta universidad. No obstante, y a pesar del poco tiempo transcurrido desde la realización de dicha catalogación, en la actualidad también se desconoce el paradero de este documento. Véase Gerardo Luzuriaga, «La Biblioteca de la Universidad de Oñati», Bilduma: Revista del Servicio de Archivo del Ayuntamiento de Enterría, no 18, 2004, p. 270.

33. Cito por la edición de Mayans, que probablemente es la que utilizaba como base para hacer sus anotaciones. Diego de Saavedra, República literaria, Gregorio Mayans (ed.), Valencia, Antonio Balle, 1735, p. 2. 
En esta ocasión, además de explicar los motivos por los cuales el narrador empezó a tener un sueño determinado, Mayans aprovecha para desplegar una lista de autores que ya habían cultivado el somnium humanista, que se había convertido en uno de los principales géneros de la prosa culta del siglo XVII. Entre ellos se encuentran Francisco de Quevedo, Justo Lipsio, Lluís Vives, Cicerón, Macrobio y también Lorenzo Van der Hammen, a quien Mayans otorga la autoría de la Casa de los locos de Amor.

En otros casos, las anotaciones pretenden defender la autoría saavedriana de la obra, que ya en esos momentos había sido puesta en entredicho ${ }^{34}$. A propósito de la utilización de la expresión «facilidad de la imprenta» en República literaria ${ }^{35}$, Mayans aprovecha para señalar que esta misma sentencia fue utilizada por Saavedra en sus Empresas Politicas ${ }^{36}$, una coincidencia que según él, indicaba que ambos textos salieron de la pluma del mismo autor ${ }^{37}$.

Otras muchas glosas son acotaciones de carácter erudito y más literario, como por ejemplo la que aparece a propósito del término "cañones» que introduce Saavedra: «Defendida de cañones de ánsares y cisnes, que disparaban balas de papel ${ }^{38}$ \%. Dice Mayans:

Cañones: Esto es plumas de ánsares, cisnes, que son muy buenas o como dijo cañones, que es término [equí]voco, que significa también las piezas de la artillería. Añade que disparaban balas de papel, equivocando estas discretísimamente con las pelotas de hierro que se llaman balas. ¡Admirable decir! Pero no fue D. Diego el primero que lo dijo. Adelantósele aquel ingenísimo poeta cordobés, D. Luis de Góngora, cuando con dulzura inimitable cantó así, p. $268^{39}$.

34. Recordemos que la obra se publicó por primera vez en 1655 con el título de Juicio de artes y ciencias a nombre de Claudio Antonio de Cabrera (Madrid, Juan de Paredes) y que a finales de la década de los setenta se encontró un nuevo manuscrito de República literaria, tal y como le anunció Francisco Cerdá y Rico en 1779. Véase Sònia Boadas, op. cit., p. 223-224. También por aquellos años el P. Estala había descubierto un manuscrito con la versión primitiva de la obra, y consideró que el texto que se había editado hasta el momento era una refundición apócrifa. Para la controvertida cuestión de la autoría del texto, véase Alberto Blecua, «Las repúblicas literarias y Saavedra Fajardo», Edad de Oro, no 3, 1984, p. 67-97 y Jorge García López, «Los testimonios manuscritos de la segunda redacción de República Literaria», Boletín de la Real Academia Española, no 82, cuaderno 285, 2002, p. 79-111.

35. "Como por la facilidad de la imprenta, con que se ha hecho trato y mercancía». Véase República literaria, op. cit., p. 1.

36. «Porque ya más son para sacar el dinero que para enseñar, habiéndose hecho trato y mercancía la imprenta». Diego de Saavedra, Empresas políticas, Sagrario López Poza (ed.), Madrid, Cátedra, 1999, p. 364.

37. Transcribo aquí la anotación de Mayans: «Facilidad de la imprenta. Este es uno de los lugares por el cual se prueba que esta obra es de D. Diego Saavedra, pues en sus Empresas Politicas, empresa 21, hablando del exceso del dicho, particularmente de jurisprudencia, dijo la misma sentencia casi con las mismas palabras».

38. Diego de Saavedra, República literaria, op. cit., p. 3.

39. Vale la pena precisar que la anotación se escribió en dos páginas diferentes. En el momento de redacción de esta nota, estas dos páginas debían ser sucesivas, pero posteriormente se añadió un folio con otras indicaciones entre las dos. 
A continuación transcribe la composición en que Góngora sugiere la palabra «cańones» aludiendo a su doble sentido:

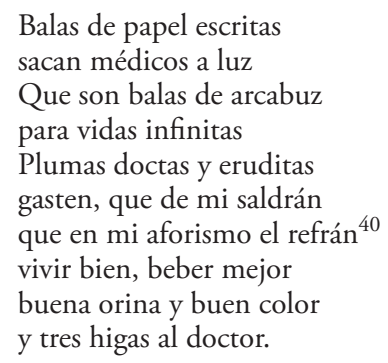

Y finalmente concluye con una frase para destacar la particular utilización del término que hizo Saavedra: «Debese a D. Diego Saavedra haber dado al equívoco un nuevo realce. Así se hacen propios los conceptos a quienes todo lo demás es hurtar».

En otros casos, Mayans consideró necesario corregir algunos errores que cometió Saavedra. Del siguiente pasaje «Pirgoteles se ocupaba en retratar a Alejandro Magno en piedras preciosas, licencia a este solo concedida, como también a Lisipo para retratarle en mármoles y bronces, y a Apeles en tablas y lienzos ${ }^{41}{ }^{1}$, comenta: "En tablas y lienzos: El pintor sobre lienzos es cosa de estos últimos siglos. Error que cometió en la hoja y siguientes.» Asimismo, a propósito del inventor del óleo, dice Saavedra: «Filodes egipcio inventó las líneas, Apolodoro el pincel y Antonelo el óleo, con que se eternizan las pinturas ${ }^{42}$ », a lo que responde Mayans: «Antonelo el óleo: No fue este el que le inventó. Véase a Palomino, libr. 1, cap. 6, párrafo 9, p. 47».

De la misma manera, hay algunas correcciones de Mayans harto interesantes y que están directamente relacionadas con los estadios de corrección de la segunda redacción de República literaria ${ }^{43}$. Recordemos que existen dos versiones de la obra, una primera escrita hacia 1612 y una segunda que se compuso por los alrededores de 1640. El texto de la segunda redacción se publicó por primera vez en 1655 bajo el título de Juicio de Artes y Ciencias, atribuida a Claudio Antonio de Cabrera. Quince años después, se imprimió por primera vez la obra con el título de República literaria y a nombre de Saavedra (Alcalá, 1670). Desde estas dos ediciones del siglo XVII, la obra no volvió a ver la luz hasta 1730 cuando Gregorio Mayans decidió publicar de nuevo el texto.

40. Parece errónea la transcripción de Mayans. De hecho, carece de sentido. La edición de Antonio Carreira propone : "[...] que de mí sabrán / que es mi aforismo el refrán : /", en Luis de Góngora, Obras completas, I, Madrid, Biblioteca Castro, 2008, p. 134.

41. Ibid., p. 10.

42. Ibid., p. 11.

43. Para las diferencias entre las dos redacciones de la obra véase John Dowling, «Saavedra Fajardo’s República Literaria», op. cit. y la «Introducción» a la edición de Jorge García López a República literaria, Barcelona, Crítica, 2006. 
Hecha esta aclaración, volvamos a las correcciones mayansianas. Una de ellas tiene que ver con el guía del narrador a lo largo del texto. En la primera redacción de la obra el cicerone era un sacerdote, pero en la segunda redacción Saavedra lo cambió por Polidoro (o Apolodoro), nombre que en un estadio de corrección posterior decidió reemplazar de nuevo por Marco Varrón. Ahora bien, en varias ocasiones, el murciano cometió algunos errores y no sustituyó de manera sistemática el nombre de «Polidoro» por el de "Marco Varrón», lo que permite reconstruir el proceso de redacción. Estos cambios se pueden atestiguar en el manuscrito Ms. 6436 de la Biblioteca Nacional de España que reproduce el texto de la segunda redacción de República literaria con las correcciones autógrafas de Saavedra de los nombres del cicerone. A raíz de una de estas menciones errónea a Polidoro ${ }^{44}$, dice Mayans:

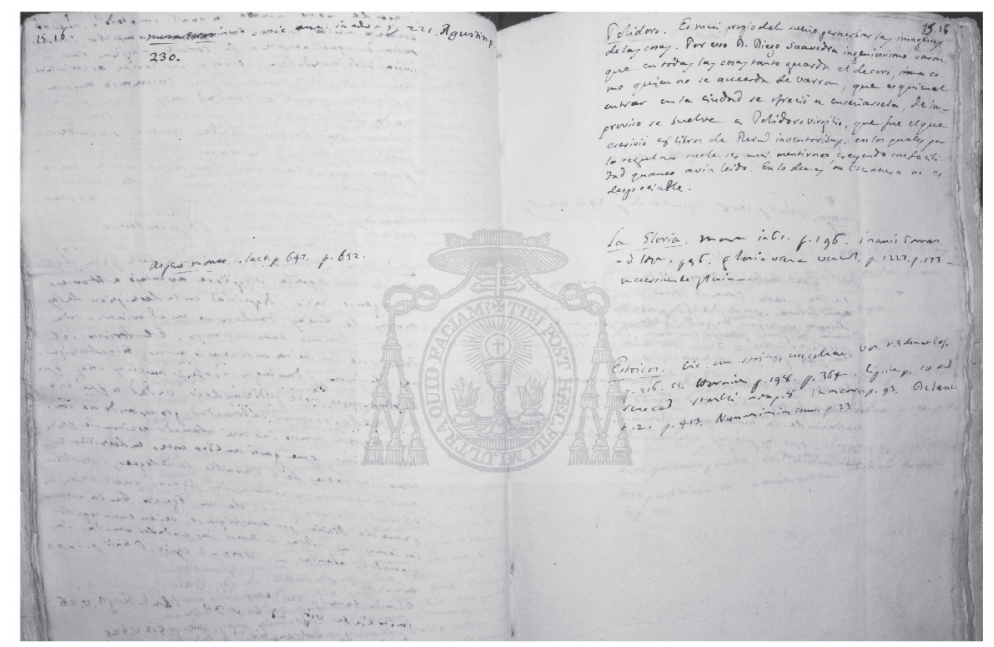

Imagen del Ms. 229 (BAHM), nota «Polidoro».

Polidoro: Es muy propio del sueńo perturbar las imágenes de las cosas. Por eso D. Diego Saavedra, ingenísimo varón que en todas las cosas, guarda el decoro, como quien no se acuerda de Varrón, que es quien al entrar en la ciudad le ofreció a enseńársela, de improviso se vuelve a Polidoro Virgilio, que fue el que escribió el libro De Rerum Inventibus, en los cuales por lo regular suele ser muy mentiroso, creyendo con facilidad cuando había leído. En lo demás su literatura no es despreciable.

Este «Polidoro» que aparece en la edición de 1730 es un error textual de Saavedra que se transmitió también en la edición de Alcalá de 1670. Un error que es fácilmente explicable y subsanable a través de la ecdótica, se resuelve, en el caso de las anotaciones mayansianas, recurriendo a la oniromancia.

Un poco más adelante, Mayans vuelve a corregir otro error textual en la obra saavedriana. En este caso se trata de una confusión en un nombre propio. Veamos cuál es el párrafo en cuestión: «Entre los últimos, aunque de los

44. «Las puertas eran de aquel bronce, o metal corintio que tanto celebró la antigüedad, gravadas con tan hermosos relieves de figuras que me obligó a preguntar a Polidoro quién era el artífice y qué historia contenían». En Diego de Saavedra, República literaria, op. cit, p. 15-16. 
primeros en el arte, estaba el Caballero Urbino acabando la estatua de Dafne, medio transformada en laurel ${ }^{45}$."

Sobre este Caballero Urbino, dice Mayans:

Urbino: Debe decir «El Caballero Vernino», de quien hace mención en el libro intitulado Aedes Barberins y el cardenal Palavicino en el Arte de Perfección, lib. 4, c. 14, p. 72. [...] Del caballero Lorenzo Vernino se hace mención en el Funeral hecho en Roma a Felipe IV escrito por don Antonio Pérez de Rúa, p. 58 y Palomino t. 3, p. 337.

Muy acertadamente Mayans percibe y corrige el error en el nombre del pintor, escultor y arquitecto italiano Gian Lorenzo Bernini -Vernino o Bernino-, a quien se describe acabando su escultura de Apolo y Dafne (16231625). El estudio de la transmisión textual de República literaria que describe el profesor García López en su edición nos permite entender el origen de este error. El manuscrito de la BNE transcribe correctamente la forma "Vernino», pero las dos ediciones posteriores, la de 1655, que apareció bajo el título Juicio de Artes y Ciencias, y la de Alcalá de 1670 transcribieron la forma "Verbino», muy posiblemente por sustitución de un fonema por la atracción de otro cercano, un error que permitiría remontar ambos impresos al subarquetipo $\beta^{46}$. Es muy probable que esta forma errónea derivara a "Urbino» en la edición mayansiana por una corrección que intentara salvar el pasaje y dotarlo de sentido, ya que Urbino es una ciudad italiana que fue importante durante el Renacimiento ${ }^{47}$. En las anotaciones, haciendo gala de su erudición, Mayans fue capaz de enmendar diligentemente el error con una corrección ope ingenii.

Asimismo, hay otra observación que llama la atención, y es la que señaló don Gregorio a partir del siguiente fragmento de República literaria:

Ponderé mucho la gravedad de estas razones y juzgue por ellas, de que aquellos libros mandaría hacer rehiletes, que a cualquier viento, y a veces sin él, se mueven al fin de quien los conduce. Y también máscaras, porque todo el estudio de los políticos se emplea en cubrir el rostro a la mentira, y que parezca verdad, disimulando el engaño y disfrazando los designios. Pero todos los mudó el fuego, y preguntándole la causa, me respondió. Este papel trae tanto veneno que aun en pedazos y por las tiendas sería peligroso al público sosiego, y si más seguro es, que le purifiquen las llamas. Algo me encogí temiendo aquel rigor en mis Empresas Políticas, aunque las había consultado con la piedad y con la razón y justicia ${ }^{48}$.

A propósito de la mención a la obra emblemática de Saavedra, escribe Mayans: «En mis Empresas políticas: Esto falta en la segunda impresión, o por malicia o porque D. Diego aún no lo había puesto». No sabemos a qué se refiere exactamente Mayans cuando habla de la «segunda impresión». De

45. Diego de Saavedra, República literaria, op. cit., p. 10.

46. Véase el stemma codicum de la obra en la edición de García López, op. cit., 115.

47. De hecho, en la primera redacción de la obra aparece mencionado el duque Urbino, q Federico II de Montefeltro (1422-1482), aunque creemos que no tiene ninguna relación con el origen del error.

48. Diego de Saavedra, República literaria, op. cit., p. 25-26. 
hecho, en el único impreso de la segunda redacción donde no aparece esta referencia es en la primera edición, la de $1655^{49}$. Parece que podría tratarse de un error por parte de Mayans, ya que además Saavedra nunca vio ninguna impresión de República literaria. A mi parecer, el erudito valenciano tiene que hacer referencia a la primera impresión de la obra (1655) donde efectivamente no aparecía la referencia a Empresas políticas, que sí aparecía en las ediciones posteriores.

Otras de las anotaciones que hizo Mayans guardan relación con algunas opiniones de Saavedra con las que estaba en claro desacuerdo. No era la primera vez que el valenciano se mostraba crítico con algunos juicios de don Diego. En la Retórica censuró distintas formas de estilo y expresiones del pensamiento saavedriano, así como criticó la utilización de los falsos cronicones en Corona Gótica $^{50}$. En este códice de anotaciones, Mayans no duda en tachar ciertas expresiones de inapropiadas y censurarlas. Este es el caso de un pasaje en el que don Diego menciona a Júpiter y a las demás deidades:

Agradecida la Religión a las demostraciones del Tajo, representa en el concilio de los dioses la obligación en que ha puesto a aquella suprema deidad de Júpiter, por quien obran las demás, no como diferentes, sino como partes producidas de su eterno ser. Pondérase en el concilio la importancia de este servicio, confiérese el permio que le compete, y casi todos concuerdan en que se le dilate al Tajo su monarquía por los términos de Europa y costas de África ${ }^{51}$.

A lo que contestó Mayans: "Como partes: Dijo en esto D. Diego un grandísimo disparate. Dios no tiene partes, ni composición alguna. [...] $Y$ casi todos: También ese modo de hablar merece censura, por suponer en Dios disensión. Si D. Diego no hablara de Dios a lo gentílico no errara tanto. Dios se lo perdona y cuantos en esto le imitan. Para mi es cosa odiosísima». Son contundentes y sentenciosas las palabras del valenciano en cuanto a la religión se refiere. No tolera el paganismo que se desprende de las palabras de Saavedra y no duda en reprobarlo.

Esta es una pequeña muestra del variado abanico de glosas y anotaciones mayansianas al texto del diplomático murciano. No hay duda de que el estudio detallado de este manuscrito permitirá a los investigadores aproximarse a la fascinación que tuvo Gregorio Mayans por Diego de Saavedra y pondrá a disposición de los estudiosos una excelente edición crítica dieciochesca de República literaria.

49. El pasaje en cuestión aparece tanto en la edición de 1670 como en el manuscrito 6436 de la BNE.

50. Véase Antonio Mestre, «La obra literaria de Saavedra vista por Mayans», Monteagudo, no 86, 1984, p. 49-53.

51. Diego de Saavedra, República literaria, op. cit. p. 19. 
